\title{
Comunicação
}

[Communication]

\section{Fatores de risco para a leptospirose em fêmeas bovinas em idade reprodutiva no Estado de São Paulo}

\author{
[Risk factors to leptospirosis in cows in São Paulo state, Brazil] \\ V. Castro ${ }^{1}$, S.S. Azevedo ${ }^{2 *}$, T.B. Gotti ${ }^{1}$, C.S.A. Batista ${ }^{1}$, J. Gentili ${ }^{1}$, Z.M. Morais ${ }^{3}$, \\ S.A. Vasconcellos ${ }^{3}$, M.E. Genovez ${ }^{1}$ \\ ${ }^{1}$ Instituto Biológico - São Paulo, SP \\ ${ }^{2}$ Unidade Acadêmica de Medicina Veterinária - CSTR-UFCG \\ Caixa Postal 64 \\ 58700-970 - Patos, PB \\ ${ }^{3}$ Faculdade de Medicina Veterinária e Zootecnia - USP - São Paulo, SP
}

A leptospirose é uma zoonose bacteriana causada por espiroquetas do gênero Leptospira. Com vasta distribuição geográfica, é evidenciada em todo o mundo e particularmente prevalente em países de clima tropical e subtropical, principalmente nos períodos de altos índices pluviométricos (Acha e Szyfres, 2001) devido à elevada sobrevivência da bactéria em ambientes úmidos, o que aumenta o risco de exposição e contaminação de animais susceptíveis e seres humanos. As perdas econômicas causadas pela leptospirose estão direta ou indiretamente ligadas às falhas reprodutivas como infertilidade $\mathrm{e}$ abortamento, bem como à queda da produção de carne e leite, além de custos com despesas de assistência veterinária, vacinas e testes de laboratório (Faine et al., 1999).

Cada sorovar de Leptospira spp. tende a ser mantido por um hospedeiro específico, por isso bovinos de qualquer região podem ser infectados com estirpes adaptadas ou mantidas pelos próprios bovinos, onde a transmissão direta é de grande importância, como ocorre com o sorovar Hardjo, que parece ser independente da região e condições climáticas, ou ainda, por estirpes mantidas por outros animais domésticos ou silvestres, o que caracteriza a infecção incidental. A infecção é determinada por fatores, como as espécies animais de contato, os sorovares existentes na região, as condições ambientais e climáticas, além do manejo e das oportunidades de infecção direta ou indireta (Ellis, 1984)

O objetivo do presente trabalho foi identificar fatores de risco para a leptospirose em fêmeas bovinas em idade reprodutiva no Estado de São Paulo.

Foram utilizados o banco de soro e o banco de dados oriundos do estudo da situação epidemiológica da brucelose bovina no Estado de São Paulo, realizado como parte do Programa Nacional de Controle e Erradicação da Brucelose e Tuberculose (Dias, 2004). Nesse estudo, foram analisados 8.216 soros de fêmeas bovinas com idade igual ou acima de 24 meses, provenientes de 1.021 propriedades, sorteadas aleatoriamente dentro de sete circuitos produtores do estado. Em propriedades com até 99 fêmeas com idade igual ou acima de 24 meses, foram amostradas 10 delas e naquelas com 100 ou mais foram amostradas, 15. As atividades de campo, realizadas por médicos veterinários no período de outubro a dezembro de 2001, incluíram a colheita de sangue e a aplicação de questionário epidemiológico por propriedade.

Como a técnica de soroaglutinação microscópica (SAM), empregada no diagnóstico da leptospirose, é a prova de referência pela Organização Mundial da Saúde (OMS) e apresenta sensibilidade e especificidade elevadas, a amostra foi extrapolada para a

Recebido em 26 de junho de 2009

Aceito em 9 de novembro de 2009

* Autor para correspondência (corresponding author)

E-mail: sergio@vps.fmvz.usp.br 
identificação de fatores de risco associados à leptospirose. A técnica foi realizada de acordo com Galton et al. (1965) e Cole et al. (1973), com uma coleção de antígenos vivos que incluiu os sorovares: Castellonis, Javanica, Tarassovi, Whitcombi, Australis, Autumnalis, Bataviae, Bratislava, Canicola, Copenhageni, Grippotyphosa, Hardjo, Hebdomadis, Pomona, Icterohaemorrhagiae, Sentot, Wolffi, Pyrogenes, Butembo, Cynopteri, Panama e Shermani. Os soros foram triados na diluição de 1:100, e aqueles que apresentaram $50 \%$ ou mais de aglutinação foram titulados pelo exame de uma série de diluições geométricas de razão dois. $\mathrm{O}$ título do soro foi a recíproca da maior diluição que apresentou resultado positivo. Os antígenos eram examinados ao microscópio de campo escuro, previamente aos testes, a fim de verificar a mobilidade e a presença de autoaglutinação ou de contaminantes.

Para o cálculo da frequência de propriedades com pelo menos um animal reagente para qualquer sorovar de Leptospira spp. no Estado de São Paulo, foi feita uma ponderação considerando o número total de propriedades por circuito produtor. Para cada um dos circuitos produtores e para os dados consolidados para o Estado foi realizado um estudo transversal para a verificação de fatores de risco. Foram, portanto, formados dois grupos de propriedades - focos e não focos - que, quando comparados entre si quanto às variáveis pesquisadas no questionário epidemiológico, permitiram medir a força da associação dessas variáveis com a presença da leptospirose. Uma propriedade era considerada foco quando apresentou pelo menos um animal soropositivo.
A análise de fatores de risco foi efetuada em duas etapas: análise univariada $\mathrm{e}$ análise multivariada. $\mathrm{Na}$ análise univariada, cada variável independente foi cruzada com a variável dependente (condição sanitária da propriedade). As que apresentaram um valor de $\mathrm{P} \leq 0,2$ pelo teste de qui-quadrado ou teste exato de Fisher, quando indicado, foram selecionadas $\mathrm{e}$ oferecidas para a análise multivariada, utilizando-se a regressão logística múltipla (Hosmer e Lemeshow, 2000). O nível de significância adotado na análise múltipla foi de $5 \%$. As análises foram feitas por circuito produtor e também no âmbito estadual, considerando reações sorológicas para qualquer sorovar e para o sorovar mais prevalente. Todas as análises foram realizadas com o programa SPSS 13.0 for Windows.

Dentre as 1.021 propriedades investigadas, 718 $(71,3 \%$; IC $95 \%=68,5 \%-74,0 \%)$ apresentaram pelo menos um animal reagente na SAM para qualquer sorovar (Tab. 1). Na Tab. 2, são apresentados os sorovares prevalentes no total de propriedades positivas do Estado de São Paulo, em que se observa o sorovar Hardjo com 55,2\% (IC $95 \%=51,4 \%$ - 58,9\%) e sua associação com o sorovar Wolffi com 20,2\% (IC 95\% $=17,3 \%$ $23,4 \%)$.

Na Tab. 3, são apresentados os fatores de risco associados à leptospirose bovina considerando reações sorológicas para qualquer sorovar, e na Tab. 4, estão listados os fatores de risco considerando reações para o sorovar Hardjo. Não foram identificados fatores de risco nos circuitos 2 e 7.

Tabela 1. Frequência de propriedades com pelo menos um animal reagente para qualquer sorovar de Leptospira spp. nos sete circuitos produtores do Estado de São Paulo, de outubro a dezembro de 2001

\begin{tabular}{ccccc}
\hline $\begin{array}{c}\text { Circuito } \\
\text { produtor }\end{array}$ & $\begin{array}{c}\text { Propriedades } \\
\text { amostradas }\end{array}$ & Propriedades positivas & Freqüência (\%) & IC 95\% $(\%)$ \\
\hline 1 & 148 & 120 & 81,1 & $73,9-86,6$ \\
2 & 166 & 135 & 81,3 & $74,6-86,6$ \\
3 & 160 & 108 & 67,5 & $59,8-74,3$ \\
4 & 153 & 117 & 76,5 & $69,1-82,5$ \\
5 & 171 & 74 & 43,3 & $36,0-50,8$ \\
6 & 134 & 88 & 65,7 & $57,2-73,2$ \\
7 & 89 & 76 & 85,4 & $76,4-91,4$ \\
\hline Estado & 1021 & 718 & 71,3 & $68,5-74,0$ \\
\hline
\end{tabular}


Tabela 2. Sorovares de Leptospira spp. prevalentes em relação ao total de propriedades reagentes no Estado de São Paulo, de outubro a dezembro de 2001

\begin{tabular}{lccc}
\hline \multicolumn{1}{c}{ Sorovar } & $\mathrm{N}$ & Frequência (\%) & IC 95\% (\%) \\
\hline Hardjo & $401 / 718$ & 55,2 & {$[51,4-58,9]$} \\
Associação Hardjo/Wolffi & $144 / 718$ & 20,2 & {$[17,3-23,4]$} \\
Shermani & $57 / 718$ & 8,0 & {$[6,1-10,3]$} \\
Grippotyphosa & $27 / 718$ & 4,4 & {$[3,1-6,3]$} \\
Autumnalis & $22 / 718$ & 3,2 & {$[2,1-4,9]$} \\
Bratislava & $16 / 718$ & 2,2 & {$[1,4-3,7]$} \\
Australis & $9 / 718$ & 1,4 & {$[0,7-2,7]$} \\
Pomona & $9 / 718$ & 1,0 & {$[0,5-2,0]$} \\
Wolffi & $6 / 718$ & 1,0 & {$[0,4-2,2]$} \\
Canicola & $5 / 718$ & 0,9 & {$[0,4-2,1]$} \\
Hebdomadis & $6 / 718$ & 0,7 & {$[0,3-1,7]$} \\
Icterohaemorrhagiae & $6 / 718$ & 0,7 & {$[0,3-1,6]$} \\
Castellonis & $3 / 718$ & 0,3 & {$[0,1-1,0]$} \\
Copenhageni & $2 / 718$ & 0,3 & {$[0,1-1,2]$} \\
Pyrogenes & $2 / 718$ & 0,3 & {$[0,1-1,2]$} \\
Butembo & $1 / 718$ & 0,1 & {$[0,02-0,9]$} \\
Whitcombi & $1 / 718$ & 0,1 & {$[0,01-0,6]$} \\
Sentot & $1 / 718$ & 0,1 &
\end{tabular}

Tabela 3. Fatores de risco para leptospirose em propriedades que apresentaram pelo menos um animal reagente para qualquer sorovar de Leptospira spp., segundo o circuito produtor do Estado de São Paulo, de outubro a dezembro de 2001

\begin{tabular}{|c|c|c|c|c|c|c|}
\hline $\begin{array}{l}\text { Circuito } \\
\text { produtor }\end{array}$ & Fator de risco & $\begin{array}{c}\text { Propriedades } \\
\text { positivas }\end{array}$ & $\begin{array}{c}\text { Propriedades } \\
\text { negativas }\end{array}$ & $\begin{array}{l}\text { Odds } \\
\text { ratio }\end{array}$ & IC $95 \%$ & $\mathrm{p}$ \\
\hline \multirow{3}{*}{1} & Tamanho do rebanho $>66$ animais & $66 / 120$ & $8 / 28$ & 3,96 & $1,51-10,41$ & 0,005 \\
\hline & Presença de suínos & $58 / 120$ & $7 / 28$ & 3,89 & $1,41-10,68$ & 0,009 \\
\hline & Existência de piquetes de parição ${ }^{*}$ & $28 / 117$ & $13 / 28$ & 0,28 & $0,11-0,71$ & 0,007 \\
\hline 2 & Tamanho do rebanho $>35$ animais & $71 / 135$ & $8 / 31$ & 3,15 & $1,31-7,53$ & 0,010 \\
\hline 3 & Tamanho do rebanho $>33$ animais & $63 / 108$ & $16 / 52$ & 3,35 & $1,62-6,91$ & 0,001 \\
\hline \multirow{2}{*}{4} & Tamanho do rebanho $>43$ animais & $42 / 71$ & $32 / 82$ & 3,31 & $1,58-6,94$ & 0,002 \\
\hline & Existência de piquetes de parição* & $18 / 70$ & $32 / 81$ & 0,34 & $0,15-0,76$ & 0,008 \\
\hline \multirow[b]{3}{*}{5} & Tamanho do rebanho $>24$ animais & $48 / 74$ & $36 / 97$ & 2,60 & $1,32-5,10$ & 0,006 \\
\hline & Uso de inseminação artificial & $11 / 72$ & $2 / 95$ & 5,51 & $1,11-27,3$ & 0,037 \\
\hline & $\begin{array}{c}\text { Compra de reprodutores de outras } \\
\text { fazendas }\end{array}$ & $27 / 74$ & $15 / 97$ & 2,89 & $1,34-6,24$ & 0,007 \\
\hline \multirow[b]{2}{*}{6} & Tamanho do rebanho $>27$ animais & $57 / 88$ & $8 / 46$ & 7,43 & $3,01-18,31$ & $<0,001$ \\
\hline & $\begin{array}{c}\text { Compra de reprodutores de outras } \\
\text { fazendas }\end{array}$ & $34 / 88$ & $5 / 46$ & 3,80 & $1,27-11,37$ & 0,017 \\
\hline 7 & Tamanho do rebanho $>44$ animais & $41 / 76$ & $3 / 13$ & 4,11 & $1,004-11,82$ & $<0,049$ \\
\hline \multirow{4}{*}{ Estado } & Tamanho do rebanho $>36$ animais & $418 / 718$ & $89 / 303$ & 3,03 & $2,22-4,11$ & $<0,001$ \\
\hline & Uso de inseminação artifícial & $65 / 687$ & $8 / 286$ & 2,50 & $1,16-5,41$ & 0,020 \\
\hline & $\begin{array}{l}\text { Compra de reprodutores de outras } \\
\text { fazendas }\end{array}$ & $231 / 718$ & $49 / 303$ & 1,78 & $1,23-2,55$ & 0,002 \\
\hline & Pastos compartilhados & $78 / 710$ & $17 / 302$ & 1,80 & $1,01-3,21$ & 0,047 \\
\hline
\end{tabular}

*fator de proteção 
Tabela 4. Fatores de risco para leptospirose em propriedades que apresentaram soroprevalência para o sorovar Hardjo, segundo o circuito produtor do Estado de São Paulo, de outubro a dezembro de 2001

\begin{tabular}{|c|c|c|c|c|c|c|}
\hline $\begin{array}{l}\text { Circuito } \\
\text { produtor }\end{array}$ & Fator de risco & $\begin{array}{c}\text { Propriedades } \\
\text { positivas } \\
\end{array}$ & $\begin{array}{c}\text { Propriedades } \\
\text { negativas } \\
\end{array}$ & $\begin{array}{l}\text { Odds } \\
\text { ratio }\end{array}$ & IC $95 \%$ & $\mathrm{p}$ \\
\hline 1 & $\begin{array}{c}\text { Tamanho do rebanho }>66 \\
\text { animais }\end{array}$ & $47 / 70$ & $27 / 70$ & 2,28 & $1,17-4,45$ & 0,016 \\
\hline 3 & $\begin{array}{c}\text { Tamanho do rebanho }>33 \\
\text { animais }\end{array}$ & $40 / 62$ & $28 / 98$ & 4,96 & $2,46-10,01$ & $<0,001$ \\
\hline \multirow[t]{2}{*}{4} & $\begin{array}{c}\text { Tamanho do rebanho }>43 \\
\text { animais }\end{array}$ & $42 / 71$ & $32 / 82$ & 3,31 & $1,58-6,94$ & 0,002 \\
\hline & $\begin{array}{l}\text { Existência de piquetes de } \\
\text { parição* }\end{array}$ & $18 / 70$ & $32 / 81$ & 0,34 & $0,15-0,76$ & 0,008 \\
\hline \multirow{2}{*}{5} & Criação de ovinos/caprinos & $9 / 27$ & $16 / 144$ & 3,23 & $1,19-8,72$ & 0,021 \\
\hline & $\begin{array}{c}\text { Compra de reprodutores de } \\
\text { outras fazendas }\end{array}$ & $13 / 27$ & $29 / 144$ & 3,13 & $1,29-7,58$ & 0,012 \\
\hline \multirow[t]{3}{*}{6} & $\begin{array}{c}\text { Tamanho do rebanho }>27 \\
\text { animais }\end{array}$ & $33 / 52$ & $32 / 82$ & 2,19 & $1,03-4,69$ & 0,049 \\
\hline & Criação de suínos & $27 / 52$ & $27 / 82$ & 2,12 & $1,02-4,49$ & 0,048 \\
\hline & $\begin{array}{c}\text { Compra de reprodutores de } \\
\text { outras fazendas }\end{array}$ & $23 / 52$ & $16 / 82$ & 2,63 & $1,17-5,96$ & 0,020 \\
\hline Estado & $\begin{array}{c}\text { Tamanho do rebanho }>36 \\
\text { animais }\end{array}$ & $241 / 401$ & $266 / 620$ & 1,97 & $1,53-2,55$ & $<0,001$ \\
\hline
\end{tabular}

*fator de proteção

O tamanho do rebanho apareceu como importante fator de risco para a infecção por leptospiras na maioria dos circuitos produtores. Os resultados da análise estatística mostram que a predisposição à infecção por leptospiras independe do tamanho do rebanho, uma vez que o número crítico de animais é pequeno e talvez não espelhe a média do rebanho paulista. Portanto, parece que o papel do bovino como disseminador de leptospiras independe do tamanho do rebanho, mas da possibilidade de contato entre os animais e, neste aspecto, a densidade de cabeças por área de pastejo seria o facilitador na disseminação da infecção (Genovez et al., 2004). A existência de piquetes maternidade em dois dos circuitos (1 e 4) surge como uma prática de manejo protetora contra a leptospirose.

O compartilhamento de pastagem, que é um indicador de contato indireto entre rebanhos, apontada como fator de risco no Estado, foi um fato esperado, dada a possibilidade de contaminação de pastagens e de água por animais de outras propriedades. Sabe-se que o agente, uma vez presente no ambiente, pode permanecer viável por longos períodos, dependendo das condições de umidade, temperatura e sombreamento, aumentando de forma significativa a chance de contato e infecção de um novo indivíduo susceptível, conforme mencionaram Faine et al. (1999).

Nos circuitos 5 e 6, a introdução de animais nas propriedades pela compra de reprodutores foi relevante fator de risco, o qual está de acordo com falhas na sanidade de qualquer rebanho em que as práticas preventivas não são cumpridas.

O uso de inseminação artificial, que aparece como fator de risco para leptospirose, deve ser encarado com cuidado, pois são conhecidos o melhoramento genético e, sobretudo, o sanitário que esta tecnologia pode trazer à reprodução de bovinos. Certamente, suas vantagens estão diretamente ligadas às condições de saúde do reprodutor e também ao controle de qualidade no manuseio do sêmen durante a industrialização, os quais são regidos por normas sanitárias internacionais, determinadas pela World Organization for Animal Health, e nacionais, pelo Ministério de Agricultura, Pecuária e Abastecimento (MAPA).

No circuito 5, a criação de ovinos e caprinos parece ser importante na predisposição à 
infecção pelo sorovar Hardjo. Ovinos são considerados hospedeiros de manutenção de Leptospira interrogans (Gerritsen et al., 1994). Embora os bovinos sejam os principais hospedeiros do sorovar Hardjo, o estreito convívio entre ovinos e bovinos pode propiciar a disseminação da leptospirose entre essas espécies. O mesmo ocorreu no circuito 6 , em que a criação de suínos foi apontada como fator de risco para infecção pelo sorovar Hardjo. Da mesma forma, em áreas onde ocorre contato entre suínos e bovinos, as chances de infecção de suínos por este sorovar aumentam, e estes animais podem servir de fontes de infecção para bovinos (Azevedo et al., 2006).

Palavras-chave: vaca, Leptospira spp., fatores de risco

\section{ABSTRACT}

Risk factors associated to leptospirosis were identified in cows from São Paulo State. The State was divided into seven productive circuits from which 8,216 cows older than 24 months of age from 1,021 herds were sampled. For serological diagnosis of Leptospira spp. infection, the microscopic agglutination test (MAT) was carried out. Of the investigated herds, $718(71.3 \%$; 95\% CI $=68.5 \%-$ $74.0 \%)$ presented at least one reactant animal at MAT to any serovar. Serovar Hardjo was the most prevalent, with 55.2\% (95\% CI = 51.4\% - 58.9\%) of the positive herds. Herd size, animal purchase, share pasture, presence of ovine and swine, and utilization of artificial insemination were identified as risk factors. Utilization of maternity pens was a protective factor against leptospirosis.

Keywords: cow, Leptospira spp., risk factors

\section{REFERÊNCIAS BIBLIOGRÁFICAS}

ACHA, P.N.; SZYFRES, B. Zoonosis y enfermidades transmissibles comunes al hombre y a los animals. Bacteriosis y micosis. 3.ed. Washington: OPS, 2001. v.1, 398p.

AZEVEDO, S.S.; SOTO, F.R.M.; MORAIS, Z.M. et al. Frequency of anti-leptospires agglutinins in sows from a swine herd in the Ibiúna municipality, State of São Paulo, Brazil. Arq. Inst. Biol., v.73, p.97-100, 2006.

COLE, J.R.; SULZER, C.R.; PULSSELY, P.R. Improved microtechnique for the leptospiral microscopic aglutination. Appl. Microbiol., v.5, p.976-980, 1973.

DIAS, R.A. Caracterização espacial da brucelose bovina no Estado de São Paulo. 2004. 112 f. Tese (Doutorado) - Faculdade de Medicina Veterinária e Zootecnia, Universidade de São Paulo, São Paulo.

ELLIS, W.A. Bovine leptospirosis in the tropics: prevalence, pathogenesis and control. Prev. Vet. Med., v.2, p.411-421, 1984.
FAINE, S.; ADLER, B.; BOLIN, C. et al. Leptospira and leptospirosis. 2.ed. Melbourne: MediSci, 1999. 272p.

GALTON, M.M.; SULZER, C.R.; SANTA ROSA, C.A. et al. Application of a microtechnique to the agglutination test for leptospiral antibodies. Appl. Microbiol., v.13, p.81-85, 1965.

GENOVEZ, M.E; OLIVEIRA, J.C.F.; CASTRO, V. et al. Serological profile of a nelore herd presenting endemic leptospirosis and submited to vaccination. Arq. Inst. Biol., v.71, p.411-416, 2004.

GERRITSEN, M.J.; KOOPMANS, M.J.; PETERSE, D. et al. Sheep as maintenance host for Leptospira interrogans servar Hardjo subtype Hardjobovis. Am. J. Vet. Res., v.55, p.1232-1237, 1994.

HOSMER, D.W.; LEMESHOW, S. Applied logistic regression. New York: John Wiley \& Sons, 2000. 375p. 